\title{
Preface: Why Heisenberg?
}

Why Heisenberg? Werner Heisenberg (rgor -76$)$ is at once an emblem of twentiethcentury physics and of the crisis of German culture and society during the Hitler period. Heisenberg's invention and development of matrix mechanics in 1925 in rivalry with Erwin Schrödinger's wave mechanics rescued traditional quantum theory from its various impasses and opened the way to the quantum mechanics that has dominated physical thinking in the last three-quarters of a century. This breakthrough, along with his formulation of the Uncertainty Principle in 1927, has assured Heisenberg a permanent place among the great physicists-an achievement recognized by the award of the Nobel Prize in 1933.

But in that same year Hitler came to power, and though Heisenberg might well have preferred not to think about him, Hitler opened the door to a crise de conscience for German physicists, as well as for the rest of the German cultural elite: Should we stay on (some asked themselves) and keep quiet, waiting for the storm to pass? Or was open protest, accompanied or not by actual political resistance, a viable alternative? Or again, was the only proper course of action to pack up and leave Germany and resist from outside? Heisenberg made a firm decision, reaffirmed during the six years before the outbreak of the Second World War in 1939, to stay on. The extent to which he agreed or disagreed politically with the Nazi regime has been a matter of bitter controversy for the last sixty years. But the point on which recrimination - and apology too - have focused has been Heisenberg's participation in the Nazi atomic bomb project. And here there is indeed massive uncertainty and disputation. On the purely scientific and technical side, did Heisenberg understand accurately how an atomic bomb would work and how to make it? And from the political and ethical point of view, did Heisenberg recognize the moral problem of becoming involved in the bomb project at all, let alone actually producing one for Hitler's use? 
Since the war an apologetic campaign has been mounted by Heisenberg and other German physicists and historians to demonstrate that he understood fully both the moral and scientific issues involved in his work as chief physicist for the Nazi atomic bomb project from 1939 to 1945 . Unsurprisingly, this has been countered on many fronts by less sympathetic American and British critics. The present book attempts to penetrate Heisenberg's mask to reconstruct his thinking and sensibility, and his conceptions of politics, morality, and duty. It will try to explain how his purely scientific work on the project must be set firmly in the German cultural climate and social context in which he always saw himself firmly situated. As Heisenberg himself avowed, he was above all a German. If we are to understand Heisenberg as he really was, we must enter into the German frame of mind, or mentality, or mind-set and sensibility, that had evolved out of the German culture of the nineteenth and twentieth centuries, strange though that mentality appears now to non-Germans, and even to those Germans who have been shaped by the changed and Westernized German culture that has been developing since 1945 .

I cannot say that my British background has made me entirely sympathetic to German culture. Although I would be the first to admit its outstanding achievements in science, music, and intellectual life in general, its insistent abstraction as well as the more sinister traditions that accompanied it induce in me a certain skepticism and even aversion. As the American liberal philosopher John Dewey once observed, even Kant's categorical imperative has a whiff of the Prussian drill sergeant about it; the grand moral principle depended, despite its apparent universal reasonableness, on an all too German demand for conforming obedience. Some readers may be put off by what seems, following this spirit of distrust of Kant, the Tendenz of the present book, its lack of sympathy with German culture, and its seeming moral and scientific denigration of a great physicist who found himself born into an evil time. Some may also find distasteful the recurrent moral judgments passed on Heisenberg, and ask what I-or anyone else-would have done if placed in Heisenberg's position in Nazi Germany. Who made me a judge over Heisenberg? But this is to mistake the proper role of the historian, which is to reconstruct the historical truth, and then, in cases where moral judgment is clearly required, to judge as fairly as one may, either by implicit suggestion and shaping of the material, or by more open statement where the conceptual and analytical elements are often obscured or misunderstood. This role does not require the historian personally to be a moral paragon or blameless. Consequently, the truth of any historical or moral portrait of Heisenberg cannot be discredited merely by stating that the historian needs to have been in Heisenberg's shoes before being able to judge. Certainly, any historian should be able to think himself or herself by an effort of historical imagination into Heisenberg's predicament, but that sort of empathetic understanding is something quite different from sympathetic abstention from moral judgments. The only real test of the historical truth of the present reconstruction is whether it makes better sense of the central problems of the Heisenberg affair and conforms more exactly to the facts as far as we may know them 
about Heisenberg, the German atomic bomb project, and German culture and society before, during, and after the Third Reich than do other versions.

This book began as a chapter in an intended book of essays that would explore the mentality and sensibility of a selection of German cultural figures who found themselves facing what one might have thought to be moral dilemmas during the Hitler years. These figures included Furtwängler, Heidegger, Heisenberg, Riefenstahl, and Jünger, among others. I had originally expected the Heisenberg chapter to be straightforward. It turned out otherwise, and the resolution of the difficulties of the case-stemming from both its scientific and its moral obscurities-have taken me nearly fourteen years to resolve. During this period, which was spent in Australia, Israel, Canada, and the United States, I was able to become more familiar with German patterns of thought and behavior through detailed work on such major cultural emblems as Kant, Fichte, Wagner, and Thomas Mann, as well as a range of lesser-known antisemitic thinkers. This increasing familiarity has convinced me of the difference and alienness - in a word, uniqueness-of German life and thought in recent centuries, and of the enduring nature of what one might call the "deep culture" of Germany. Readers are free to accept or reject my characterizations, but I hope that in neither case will they accuse me of unthinkingly preaching a crude view of German "national character," whatever that term may mean. I also hope they will not dismiss out of hand the central thrust of the book: It is only by understanding Heisenberg in his specifically German context that we are likely to come to a true knowledge of his political and moral behavior and attitudes, as well as his scientific activity, during the Nazi era. In insisting on this German context, I believe I am being historically true to Heisenberg's own perception and priorities, for he saw himself in the end as a German more than even as a physicist.

In this book I have tried to penetrate into how Germans think-or rather, perhaps, used to think - and to show how radically different are German and what I have termed "Western" mentalities and sensibilities. My regret is that in order to expose the nature and fallacies of much of this German thinking and feeling, I have, I fear, often been forced to be tediously analytical. This is not, in consequence, a graceful book, I am sorry to confess, but perhaps Heisenberg and company have benefited too long from grace of various sorts. 
